\title{
Proposed Conceptual Design Model of Persuasive Game for Upper limb for Stroke Rehabilitation
}

\author{
Mohd Yusoff Bin Omar \\ Computer Information Sciences \\ Department: \\ Universiti Teknologi PETRONAS \\ Seri Iskandar, Perak, Malaysia \\ yusoff_16002206@utp.edu.my \\ Mohd Fairuz Shiratuddin \\ School of Engineering and Information \\ Technology, \\ Murdoch University, \\ Perth, Australia \\ f.shiratuddin@murdoch.edu.au
}

\author{
Dayang Rohaya Awang Rambli \\ Computer Information Sciences \\ Department: \\ Universiti Teknologi PETRONAS \\ Seri Iskandar, Perak, Malaysia \\ dayangrohaya.ar@utp.edu.my \\ Frédéric Merienne \\ LISPEN EA7515, Arts et Metiers, \\ HESAM,UBFC, Institut Image, \\ France \\ frederic.merienne@ensam.eu
}

\author{
Suziah Sulaiman \\ Computer Information Sciences \\ Department: \\ Universiti Teknologi PETRONAS \\ Seri Iskandar, Perak, Malaysia \\ suziahs@utp.edu.my \\ Delphine Vanhalle \\ LISPEN EA7515, Arts et Metiers, \\ HESAM,UBFC, Institut Image, \\ France \\ delphine.vanhalle@yahoo.fr
}

\begin{abstract}
The gamification of stroke rehabilitation may increase patient's motivation and engagement towards their rehabilitation activity and hence contributes to faster recovery. Apart from the interactive experience that games offer, it also may be used as a persuasive tool. In this view, games may be used to persuade stroke patients in shaping a good behavior towards their rehabilitation activity. This paper reports our proposed conceptual design model of building persuasive game for stroke patients that follows the Persuasive System Design Model. We incorporate the persuasive software features that includes reduction, tailoring, self-monitoring, and rewards. The proposed game architecture is also discussed in this paper.
\end{abstract}

Keywords - Stroke Rehabilitation Game, Kinect Game, Conceptual Model, Game architecture

\section{INTRODUCTION}

Game based stroke rehabilitation has gained a lot of attention lately [1-3]. This is because the gamification of stroke rehabilitation may increase patient's engagements and affect their result positively [1]. In addition, the wide availability of low cost game technology employing motion sensors such as Kinect camera (or commonly known as exergame) and their adequate accuracy contribute to the development and proliferation of such study [3].

Apart from entertaining the players, game also can be used as persuasive technology through its rich interaction that includes multimedia elements (eg: video, audio, graphics) and interactive experiences offered in the gameplay [4]. With the provision of fun experience, game can also can persuade stroke patients in shaping a good behavior and attitude towards their rehabilitation therapy. This is necessary because many stroke patients were reported as not motivated to continue with their rehabilitation at home and being highly dependent on rehabilitation services from therapists and hospitals [2]. Through the gamification of rehabilitation activity, patients may become more motivated and engaged in their rehabilitation therapy and may recover faster consequently. This may bring future benefits because the global burden of stroke is increasing due to the aging populations and the worrying trend of stroke that start attacking young adults [5].

To the best of our knowledge, there is limited literature about designing persuasive game for stroke patients. Therefore, we develop the conceptual persuasive game design for stroke rehabilitation following the Persuasive System Design (PSD) Model from our previous work [6]. This paper describes the persuasive features implementation, the game architecture and its modules.

\section{RELATED WORK}

There have been many studies about incorporating game technology in stroke rehabilitation. The principle of this study are to provide patients with interactive user interface and to implement different task scenarios. Such studies can be divided under customized development category and adoptions of commercial games category [2].

Motion Rehab AVE 3D is an example of customized game that requires patients to follow an avatar performing ball juggling with their hands and legs by the beach [7]. An assessment of a cooking game, Kinelabs, concluded that the game may contribute to the improvement chronic stroke patients [8]. The development of a sword fighting game which requires patients to wear VR headset and robotic exoskeleton arm is able to accurately map the patient's limb in 3 dimensional spaces and may support arm rehabilitation [9].

Some adoptions of commercial exergame for stroke rehabilitation can be found such as, Kinect Sports package [10], Kinect Adventure [11] and Nintendo Wii [12]. These studies showed that these commercial games adoptions were showed significant patients improvement's and appeared to be safe and feasible for rehabilitation. However, not many commercial games adoption are suitable for rehabilitation purposes due to the interaction that requires full range of motion and fast movements of a normal and healthy player and therefore may be too difficult for stroke patients $[2,13]$. Some games also are reported as costly and difficult for therapists to setup [13].

Many of game based stroke rehabilitation need further strategic and longitudinal study and also with more variety of games to gain more understandings. Aminov et al. [14] has reviewed the randomized controlled trials and concluded that game applications can give significant improvement on patient's outcomes and encouraged more games implementation research. Similarly, Bonnechère et. al [15] suggested that games applications may prevent monotonous and boring rehabilitation and suggested that specific game for rehabilitation may produce better therapeutic outcome. In addition, Laver et al. [1] suggested that games applications showed more beneficial when games are used for additional rehabilitation activity but not to replace the conventional rehabilitation activity. 
However, the use of exergame for rehabilitation is seemed as underutilized. The ability to store vast amount of data from gameplay sessions such as which games have been played and how much the player moves can provide information for rehabilitation adherence study. In addition, a personalized and tailored system's content and delivery for rehabilitation purpose also suggested because in this context, there is no 'one size fits all' approach due to the variety of the patients' needs and conditions [16]. To use game as a persuasive technology, the persuasion context analysis from Persuasive System Design (PSD) model should be identified to prevent 'ad hoc' and 'black box' system development approach [17]. An example of PSD Model application can be found in iLift [18]. This Kinect based game's study purpose is to train nursing personnel to practice a proper lifting and transfer technique in performing their daily ward tasks. The results showed that the participants exhibited a correct lifting technique as they progressed further in playing the game.

\section{Persuasive Game DeVelopment}

As an exploratory study, our focus is developing a persuasive game by following the PSD model [19]. The purpose of our game is to persuade stroke patients to comply to the rehabilitation exercise as advised by therapist. This can be done by providing game environment that offer rich interactions to the patients. From the second step of PSD model, we provide the persuasion context analysis which involve describing the persuasion intent, persuasion event and the persuasion strategy (see Table 1).

In following the third step of the PSD Model, we select and discuss selected four persuasive software features which are reduction, tailoring, self-monitoring and reward to be implemented in our proposed game.

From the fishing game scenario [6], we emulated the upper limb shoulder with straight arm movement that ranges from 90 to 120 degrees (see Fig. 1). This slow and careful with high repetition of shoulder and straight arm movement will exercise the shoulder muscle and can improve the patient's quality and range of motion and subsequently can prevent shoulder dislocation and muscle stiffness [20]. To do this, the game should have reduction feature as to simplified the gameplay activity from a complex arm movement (that involving various parts of joints such as shoulder, elbow and fingers) to a task specific movement (that involving only the shoulder with a straight arm). This would enable the patient to just concentrate on performing the rehabilitation therapy. In addition, the game should allow the patient to play in sitting position instead of standing up in order to maintain balance and ensure safety [16].

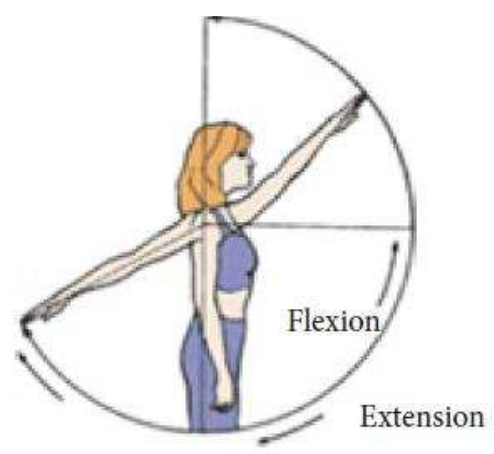

Fig. 1. Gross Motor Upper Limb Movement [21]
TABle I. Persuasion CONTEXT Analysis [6]

\begin{tabular}{|c|c|}
\hline Intent & Description \\
\hline Persuader & $\begin{array}{l}\text { - The rehabilitation center and therapist are the } \\
\text { persuader } \\
\text { - The game is designed with autogenous type of } \\
\text { intent whereby the patient will } \\
\text { become influenced as s/he play the game } \\
\text { continuously }\end{array}$ \\
\hline $\begin{array}{l}\text { Intended } \\
\text { Outcome/Change }\end{array}$ & $\begin{array}{l}\text { - The aim of this game is to form a compliance } \\
\text { of rehabilitation activity as suggested by the } \\
\text { therapist }\end{array}$ \\
\hline Event & Description \\
\hline Use Context & $\begin{array}{l}\text { - The objective of the game is to provide game } \\
\text { environment for the patient to perform } \\
\text { rehabilitation exercise } \\
\text { - The game is made for gross motor upper limb } \\
\text { rehabilitation. } \\
\text { - The game allows goal settings by the therapist } \\
\text { and store the patient's profile and game record } \\
\text { - The game will be played in rehabilitation } \\
\text { center under therapist's guidance and } \\
\text { assistance }\end{array}$ \\
\hline User context & $\begin{array}{l}\text { - Advanced stroke patients who are able move } \\
\text { the impaired arm with a limited range of } \\
\text { motion } \\
\text { - Patient that has no ability to move impaired } \\
\text { arm may be assisted by using their normal arm } \\
\text { - Therapists may adjust the targeted number of } \\
\text { repetition in the game setting }\end{array}$ \\
\hline $\begin{array}{l}\text { Technology } \\
\text { context }\end{array}$ & $\begin{array}{l}\text { - The game will be developed using Unity and } \\
\text { Kinect motion sensor to capture arm } \\
\text { movement }\end{array}$ \\
\hline Strategy & Description \\
\hline $\begin{array}{l}\text { Message and } \\
\text { Route }\end{array}$ & $\begin{array}{l}\text { - The message is to keep the patients in } \\
\text { performing their rehabilitation activity by } \\
\text { following the game's rule and the repetition } \\
\text { that is set by the therapist. }\end{array}$ \\
\hline
\end{tabular}

The game should also have tailoring feature because depending on the severity of the stroke incident, a patient may have a very limited range of motion. For this reason, the target placement in the game should be adaptable to the patient's current ability. As suggested in [13] [16], there are variety of needs and conditions of rehabilitation purposes that demand different treatment and therefore the task and target in a game activity should be different form one patient to another. In some cases for example, patient may need to use his other hand to lift up his totally paralyzed arm to exercise the shoulder muscles.

Self-monitoring feature should be implemented in the game as the patient may want to see the progress that they have achieved [13]. This can be done by allowing the game to save the patient's gameplay data such as points, badges, levels, and/or video recording of game session. This data can be used by the therapy to discuss current progress, achievement and further treatment plan with the patient [16]. In addition, the exergame feature that shows an avatar representing the player's body movement can provide a direct feedback for the patient in performing the arm movement [22].

As for the highly repetitive motion that is required, the game should provide reward for a completed repetition that is targeted in a rehabilitation session. This commonly applied game element should be implemented as well in the proposed game to indicate a successful task completion [23]. An example of reward in game are coins or badges collection that can unlock further levels of gameplay. This feature would enhance patient's motivation and engagement in their rehabilitation therapy while playing the game [22]. 


\section{Proposed Conceptual Game Design}

From the persuasion context analysis and the selected persuasive features that were discussed earlier, we then propose the conceptual game design for upper limb stroke rehabilitation. Our proposed fishing game can be described in 3 main modules of game architecture (see Fig. 2). Firstly, the 'game module' which consists of an assessment of patient's current range of motion and also the 'fishing activity'. Secondly, the 'therapy module' which records and processes data from the patients in their playing time. The last module is the 'therapist module' which allows the therapist to set the repetition of hand movement after an analyses of the patient's performance from the therapy module.

\section{A. Game module}

Before playing the game, we propose to have an assessment module of the patient's current range of motion ability. This can be done by asking the patient to clean a dirty virtual fish tank with his impaired arm. The cleaning up task may start from center-bottom of the screen and spread vertically and horizontally outward across the screen leaving a clean screen that reveal a clean view of scene of the tank (see Fig. 3). The different boundary of the clean and unclean view of the tank will be calculated as percentage shown on the top left of the game's screen and will be used as marks of the patient's current ROM and will be used to determine the target placement in the fishing scene.

After the patient's current range of motion have been assessed. The fishing game will start. The repetitive shoulder movement as previously depicted in Fig. 1 will be reflected by the game's avatar holding a fishing rod that appear on the left and also the yellow shadow on the right of game's screen (see Fig. 4). The avatar needs to hit the green circle as the target that is placed almost touching the tip of the fishing rod. As the patient moves his impaired arm, the avatar will lift the fishing rod to hit the target and it will disappear and reappear in slightly different location across the screen asking the patient to hit it again. This repetition will continue after a certain number that is set by the therapist in the therapist's module. The numbers and coins that appear on the top right indicate the marks that the patient has scored when the target is hit.

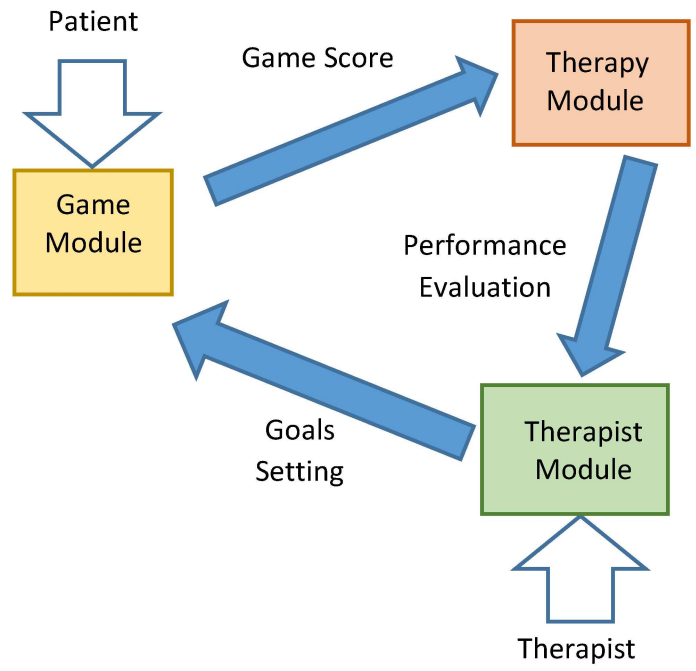

Fig. 2. Proposed Game Architecture

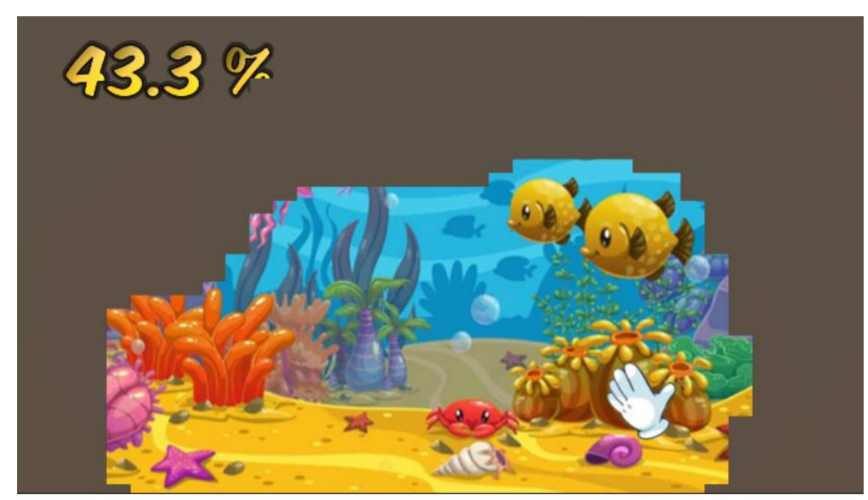

Fig. 3. Tank Cleaning Task to assess patient's current range of motion.

From the various design of games scene (such as fantasy, cozy, or sports), the nature-based game scenes were reported as the favorite across all ages of the study participants [22]. Therefore, the proposed fishing game would take place in a virtual outdoor as suggested to provide nature environment and also recreational experience for the patients. Other game scene design like fantasy-based environments that are commonly used for children game may limit the patients' acceptance, desire and adherence in completing the game and therefore may not be suitable for stroke rehabilitation purpose [13].

We also propose to use completion-focus gameplay because when age of players increase, they would prefer a task completion games as opposed to performance-focus gameplay [24]. The is reflected by the fishing game task that require the patients to complete the targeted repetition of shoulder movement as defined by their therapists. As result of task completion, the players will be rewarded with coins as depicted in top right game's screen (see Fig. 4). This task completion focus will be suitable for elderly player that suits the majority of stroke patients [25] rather than competition based game such as 'player versus other player' gameplay.

\section{B. Therapy Module}

We propose to provide a game menu for the therapist to set the repetition of hand movements that the patient needs to perform (see Fig. 5). This can be done by setting how many shoulder extension and flexion repetition should be done and how many fish that can be caught in each rehabilitation session. From the repetition that is set, the game will provide the rich interaction such as background music, sound effects, and sound of nature environment. The patient will become engaged and motivated to finish the repetition and subsequently may improve his range of motion.

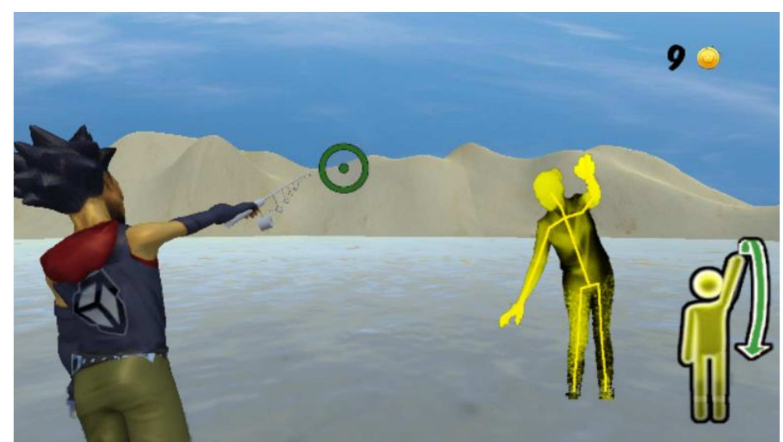

Fig. 4. Fishing game activity 


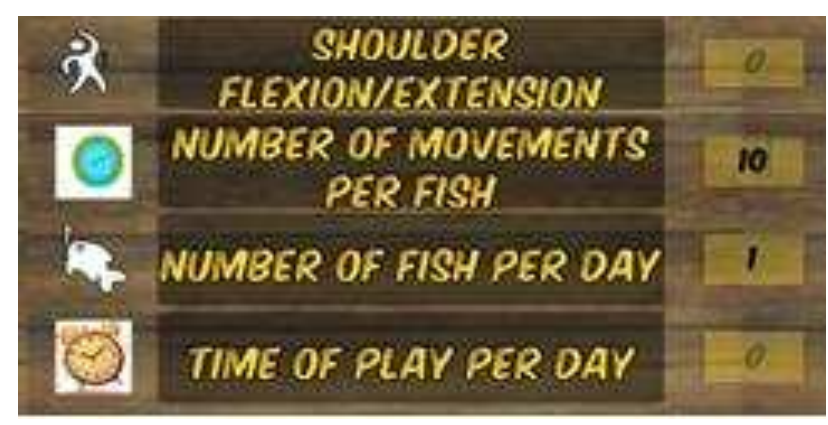

Fig. 5. Goal setting menu for therapist

\section{Therapist Module}

For the therapist module, we propose that the game should track and record the patient's arm movement. The game would translate the recordings into a graph so that the therapist can assess the patient's quality of the movement. From the sketch of the graph (see Fig. 6), an assessment can be done by looking at the line representation. For example, a good control of arm movement should be reflected by a smooth curve and a good range of motion should be reflected by a long curve. This graph can also be shared to the patient as to provide a feedback from his comparisons or achievements between rehabilitation session.

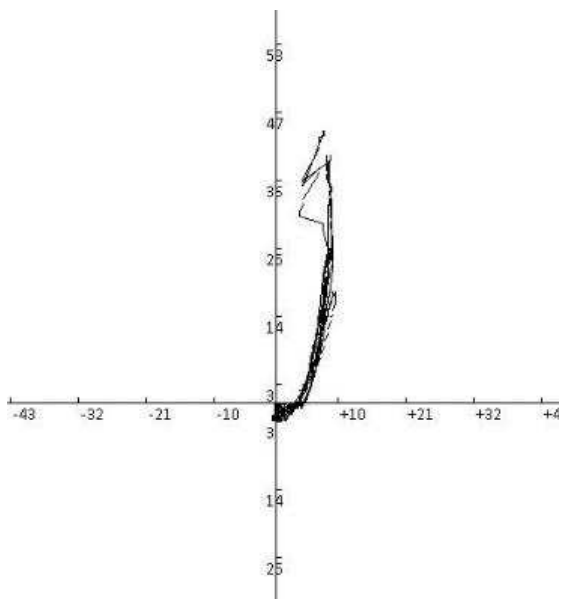

Fig. 6. An example of graph for quality of movement assessment

\section{CONCLUSION}

We have proposed a conceptual game design model that follows Persuasive Design Model and incorporated the persuasive features into the game. To the best of our knowledge, this work may contribute as the first conceptual persuasive game design model for stroke rehabilitation. With this method, a descriptive model of proposed system level can be studied and analyzed. Our next step is to develop a prototype from the proposed game design model and conduct a demonstration with therapists to get feedback before testing it with stroke patients.

\section{REFERENCES}

[1] K. E. Laver, B. Lange, S. George, J. E. Deutsch, G. Saposnik, and M. Crotty, "Virtual reality for stroke rehabilitation," Cochrane Database of Systematic Reviews, no. 11, 2017, doi: 10.1002/14651858.CD008349.pub4.

[2] Y.-X. Hung, P.-C. Huang, K.-T. Chen, and W.-C. Chu, "What Do Stroke Patients Look for in Game-Based Rehabilitation: A
Survey Study," Medicine (Baltimore), vol. 95, no. 11, p. e3032, Mar 2016, doi: 10.1097/MD.0000000000003032.

H. Mousavi Hondori and M. Khademi, "A Review on Technical and Clinical Impact of Microsoft Kinect on Physical Therapy and Rehabilitation," Journal of Medical Engineering, vol. 2014, pp. 1-16, 2014, doi: 10.1155/2014/846514.

B. J. Fogg, "Persuasive technology: using computers to change what we think and do," Ubiquity, vol. 2002, no. December, p. 2, 2002, doi: $10.1145 / 764008.763957$.

G. J. Hankey, "Stroke," The Lancet, vol. 389, no. 10069, pp. 641654, 2017, doi: 10.1016/s0140-6736(16)30962-x.

M. Y. Omar, D. R. A. Rambli, and M. F. Shiratuddin, "Designing Persuasive Stroke Rehabilitation Game: An Analysis of Persuasion Context," in Advances in Visual Informatics, Cham, H. Badioze Zaman et al., Eds., 2017// 2017: Springer International Publishing, pp. 559-569.

[7] M. Trombetta, P. P. Bazzanello Henrique, M. R. Brum, E. L. Colussi, A. C. B. De Marchi, and R. Rieder, "Motion Rehab AVE 3D: A VR-based exergame for post-stroke rehabilitation," Comput Methods Programs Biomed, vol. 151, pp. 15-20, Nov 2017, doi: 10.1016/j.cmpb.2017.08.008.

[8] A. Askin, E. Atar, H. Kocyigit, and A. Tosun, "Effects of Kinectbased virtual reality game training on upper extremity motor recovery in chronic stroke," (in eng), Somatosensory \& motor research, vol. 35, no. 1, pp. 25-32, Mar 2018, doi: 10.1080/08990220.2018.1444599.

[9] M. K. Tageldeen, I. Elamvazuthi, N. Perumal, and T. Ganesan, "A virtual reality based serious games for rehabilitation of arm," in Robotics and Manufacturing Automation (ROMA), 2017 IEEE 3rd International Symposium in, 2017: IEEE, pp. 1-6.

[10] T. A. Turkbey, S. Kutlay, and H. Gok, "Clinical feasibility of Xbox Kinect training for stroke rehabilitation: A single-blind randomized controlled pilot study," (in eng), Journal of rehabilitation medicine, vol. 49, no. 1, pp. 22-29, Jan 19 2017, doi: 10.2340/16501977-2183.

H. Sin and G. Lee, "Additional Virtual Reality Training Using Xbox Kinect in Stroke Survivors with Hemiplegia," 2013.

K. Paquin, J. Crawley, J. E. Harris, S. J. D. Horton, and rehabilitation, "Survivors of chronic stroke-participant evaluations of commercial gaming for rehabilitation," vol. 38, no. 21, pp. 2144-2152, 2016

M. Pickrell, E. v. d. Hoven, and B. Bongers, "Exploring inhospital rehabilitation exercises for stroke patients: informing interaction design," presented at the Proceedings of the 29th Australian Conference on Computer-Human Interaction, Brisbane, Queensland, Australia, 2017.

A. Aminov, J. M. Rogers, S. Middleton, K. Caeyenberghs, P. H. J. J. o. n. Wilson, and rehabilitation, "What do randomized controlled trials say about virtual rehabilitation in stroke? A systematic literature review and meta-analysis of upper-limb and cognitive outcomes," vol. 15, no. 1, p. 29, 2018.

[15] B. Bonnechère, B. Jansen, L. Omelina, and S. Van Sint Jan, "The use of commercial video games in rehabilitation: a systematic review," International Journal of Rehabilitation Research, vol. 39, no. 4, pp. 277-290, 2016, doi: 10.1097/mrr.0000000000000190.

[16] N. Skjaeret, A. Nawaz, T. Morat, D. Schoene, J. L. Helbostad, and B. Vereijken, "Exercise and rehabilitation delivered through exergames in older adults: An integrative review of technologies, safety and efficacy," Int J Med Inform, vol. 85, no. 1, pp. 1-16, Jan 2016, doi: 10.1016/j.ijmedinf.2015.10.008.

[17] S. M. Kelders, H. Oinas-Kukkonen, A. Oorni, and J. E. van Gemert-Pijnen, "Health Behavior Change Support Systems as a research discipline; A viewpoint," Int J Med Inform, vol. 96, pp. 3-10, Dec 2016, doi: 10.1016/j.ijmedinf.2016.06.022.

[18] D. A. Kuipers et al., "iLift: A health behavior change support system for lifting and transfer techniques to prevent lower-back injuries in healthcare," Int J Med Inform, vol. 96, pp. 11-23, Dec 2016, doi: 10.1016/j.ijmedinf.2015.12.006.

[19] Harri Oinas-Kukkonen and Maria Harjumaa, "Persuasive Systems Design: Key Issues, Process Model, and System Features," Communications of the Association for Information Systems, vol. 24, 28, 2009,

[20] C. J. Winstein et al., "Guidelines for Adult Stroke Rehabilitation and Recovery," Stroke, vol. 47, no. 6, pp. e98-e169, 2016, doi:10.1161/STR.0000000000000098. 

Elicitation and Prototyping of a Fully Immersive Virtual Reality Gaming System for Upper Limb Stroke Rehabilitation in Saudi Arabia," Mobile Information Systems, vol. 2017, p. 12, 2017, Art no. 7507940 , doi: $10.1155 / 2017 / 7507940$.

[22] J. F. Pinto, H. R. Carvalho, G. R. R. Chambel, J. Ramiro, and A. Goncalves, "Adaptive gameplay and difficulty adjustment in a gamified upper-limb rehabilitation," in 2018 IEEE 6th International Conference on Serious Games and Applications for Health (SeGAH), 16-18 May 2018 2018, pp. 1-8, doi: 10.1109/SeGAH.2018.8401363.

[23] R. M. Hannah and K. H. Amanda, "Gamification: Applications for Health Promotion and Health Information Technology Engagement," in Handbook of Research on Holistic Perspectives in Gamification for Clinical Practice. Hershey, PA, USA: IGI Global, 2016, pp. 78-104.

[24] M. V. Birk, M. A. Friehs, and R. L. Mandryk, "Age-Based Preferences and Player Experience: A Crowdsourced Crosssectional Study," presented at the Proceedings of the Annual Symposium on Computer-Human Interaction in Play, Amsterdam, The Netherlands, 2017. [Online]. Available:

[25] E. S. Donkor, "Stroke in the 21(st) Century: A Snapshot of the Burden, Epidemiology, and Quality of Life," Stroke Res Treat, vol. 2018, p. 3238165, 2018, doi: 10.1155/2018/3238165. 